\title{
Revascularization of a Crushed Foot and Ankle Mortis
}

James El Haddi ${ }^{1}$, Veronica Garbar ${ }^{1}$, Lawrence Lottenberg ${ }^{2}$, Robert Borrego ${ }^{2}$, Mario Rueda ${ }^{3}$

1. Surgery, Florida Atlantic University Charles E. Schmidt College of Medicine, Boca Raton, USA 2. Surgery, Florida Atlantic University/St. Mary's Medical Center, West Palm Beach, USA 3. Trauma, Florida Atlantic University/St. Mary's Medical Center, West Palm Beach, USA

Corresponding author: James El Haddi, selhaddi@health.fau.edu

\begin{abstract}
Foot crush injury is a difficult problem both from the complexity of the injury pattern standpoint and also the significant clinical and socioeconomic burden that it represents to the patient. Scoring systems exist to predict limb salvage, but the accuracy and implementation of these are varied, and thus clinical judgment must always be employed when attempting limb salvage. This case report describes the first use of a reversed saphenous interposition graft repair of a transected dorsalis pedis in a patient after sustaining crush injuries to the distal lower extremity. The patient was able to undergo partial limb salvage with the use of revascularization and judicious fasciotomies.
\end{abstract}

Categories: Cardiac/Thoracic/Vascular Surgery, General Surgery, Trauma

Keywords: extremity, extremity trauma, crush injury, trauma, revascularization, vascular surgery, amputation, limb salvage

\section{Introduction}

Distal extremity crush trauma is often a challenge for management because orthopedic, soft tissue, vascular, and nerve injuries are frequently intermixed. Salvaging limbs following blunt distal extremity trauma is an extremely arduous process for the clinician, and the salvage rate is lower than penetrating injuries [1]. Though studies have shown that while early amputation may decrease hospital length of stay and readmission [2], military data suggests that long-term psychological and functional outcomes may be similar regardless of salvage attempts [3]. In the civilian population, return-to-work times are of the utmost importance. These are dependent on multiple factors including the need for operative intervention, patient age, and location/extent of injuries [4]. Vascular injury can significantly affect rates of limb salvage and return-to-work times [5].

Received 10/05/2020 Review began 10/08/2020 Review ended 11/06/2020 Published 11/19/2020

\section{() Copyright 2020}

El Haddi et al. This is an open access article distributed under the terms of the Creative Commons Attribution License CC-BY 4.0., which permits unrestricted use, distribution, and reproduction in any medium, provided the original author and source are credited.
When evaluating in the trauma bay, multiple risk scores have been devised to predict which patients may have successful limb salvage [6-7]. Recent meta-analyses and retrospective studies have suggested that while popular scores such as the Mangled Extremity Severity Score (MESS) and Gustilo-Anderson classification have been widely accepted for risk stratification, they are often incorrectly employed and may have poor predictive value [7-8]. Unsuccessful limb salvage brings multiple interventions, hospital readmissions, and delayed rehabilitation. Because of these risks, there is a need to predict which patients should even undergo initial attempts at limb salvage versus amputation. The rate of amputations for all causes (traumatic and nontraumatic) is as low as 43\% [9] with quality of life and function dependent on the level of amputation [10]. Patients who suffer traumatic extremity injuries tend to be low-income, uninsured, and unskilled manual laborers, which further amplifies the socioeconomic burden [11]. In the following case, we describe the use of unique limb-salvage technique in a patient with a presenting MESS core of 6 and a Gustilo-Anderson score of $3 \mathrm{~b}$.

\section{Case Presentation}

The case in question involves a 44-year-old male who sustained a crush injury to both lower extremities after being run over by a large utility vehicle. In the trauma bay, he was noted to have a degloving injury of the distal right lower extremity in combination with an open fracture and non-pulsatile bleeding. Biphasic pedal signals were identified bilaterally during resuscitation. Plain films revealed open displaced fractures to right metatarsals 2-4 and displaced right medial malleolar and tibial metaphysis fractures with a spiral fracture of the proximal fibula as shown in Figure 1. His MESS score was 6, and Gustilo-Anderson score was $3 \mathrm{~b}$, which are not predictive of needing amputation but do predict an elevated risk of complication. The patient did undergo computed tomography angiography (CTA) of the extremities, which showed three-vessel runoff to the level of the malleolus with a transection of the dorsalis pedis. The orthopedic surgery team took the patient to the operating room where he underwent debridement of nonviable tissues with reduction of the fractures and placement of a negative pressure wound therapy system. Postoperatively the patient's extremity was warm with palpable dorsalis pedis pulse. During rounds on hospital day three, the patient was noted to have a cool and pulseless foot distal to the malleolus, which is suggestive of ischemia. Therefore, the patient was taken urgently to the operating room by trauma surgery service. His preoperative wound is 


\section{Cureus}

shown in Figure 2.

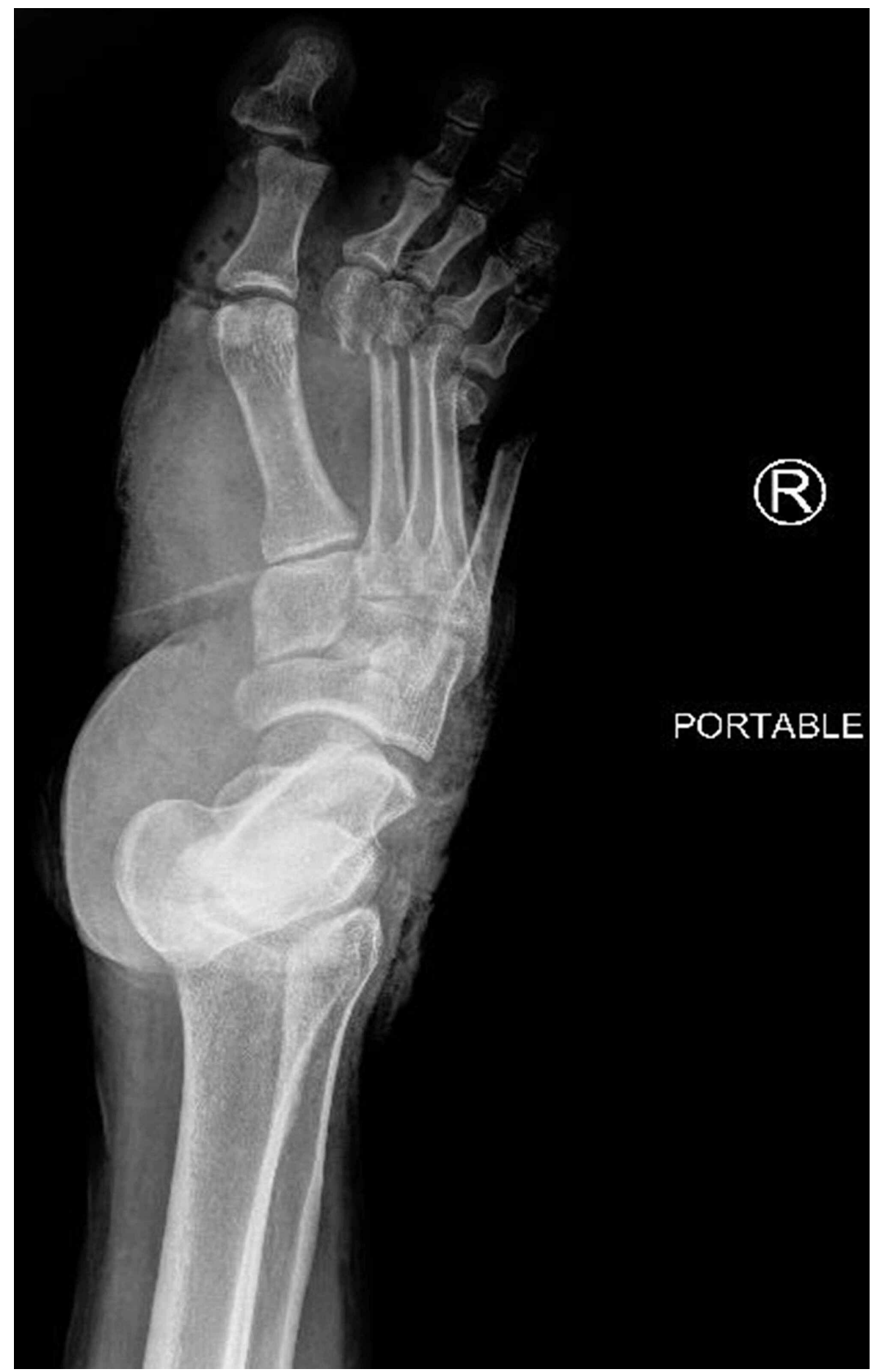

FIGURE 1: Plain film x-ray of the patient's crushed foot obtained in the trauma bay

Plain film x-ray of the patient's right lower extremity. Note the displaced fractures of metatarsals 24 , displaced right medial malleolar, and tibial metaphysis fractures. 


\section{Cureus}

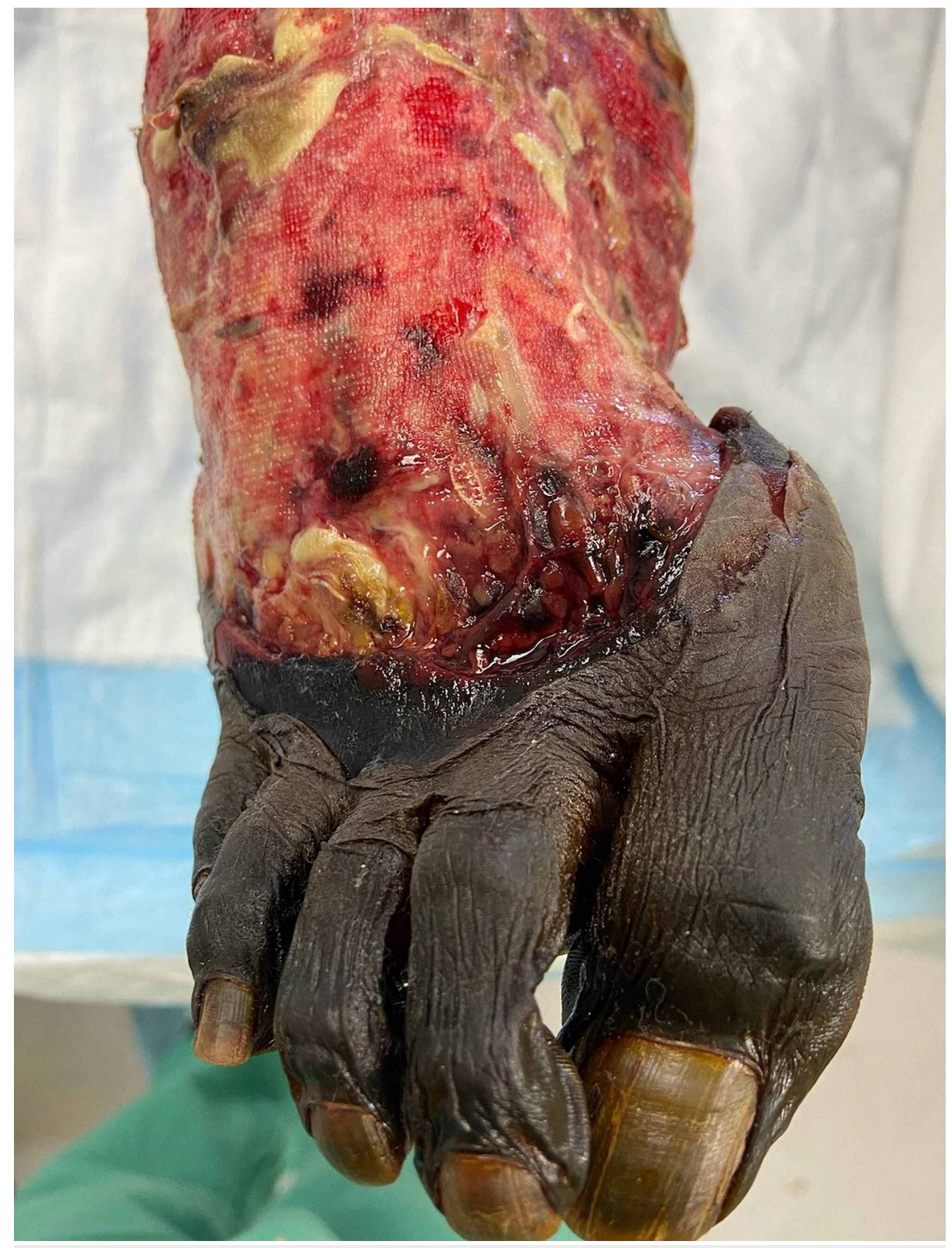

\section{FIGURE 2: The patient's crushed right lower extremity prior to revascularization}

Here we see the patient's right lower extremity prior to revascularization. Significant nonviable tissue debridement and reduction of the open fractures had been completed by the orthopedic consultants.

In the operating room, the dorsalis pedis artery was exposed at the level of the ankle as identified by Doppler signals. This was exposed distally until a complete transection was identified $2 \mathrm{~cm}$ distal to the ankle. The distal portion was identified proximal to the webspace. Necrotic tissues were resected, and the vessel underwent embolectomy to restore brisk bleeding from the proximal segment before flushing and systemic heparinization. Distal greater saphenous vein was dissected, and an 8-cm segment was utilized to create a reversed interposition graft with spatulation of the ends. Fasciotomies were performed in the forefoot, and hematomas were evacuated from the compartments due to the presence of compartment syndrome. The wounds were packed with gauze, and, given the lack of nearby viable tissue for complete coverage, the exposed vessels and anastomosis were covered with Integra ${ }^{\mathrm{TM}}$ (Integra LifeSciences, Princeton, NJ) before wrapping in bismuth-laden petroleum gauze and dry gauze. Postoperative images of the patient's revascularized wound are shown in Figure 3. 


\section{Cureus}

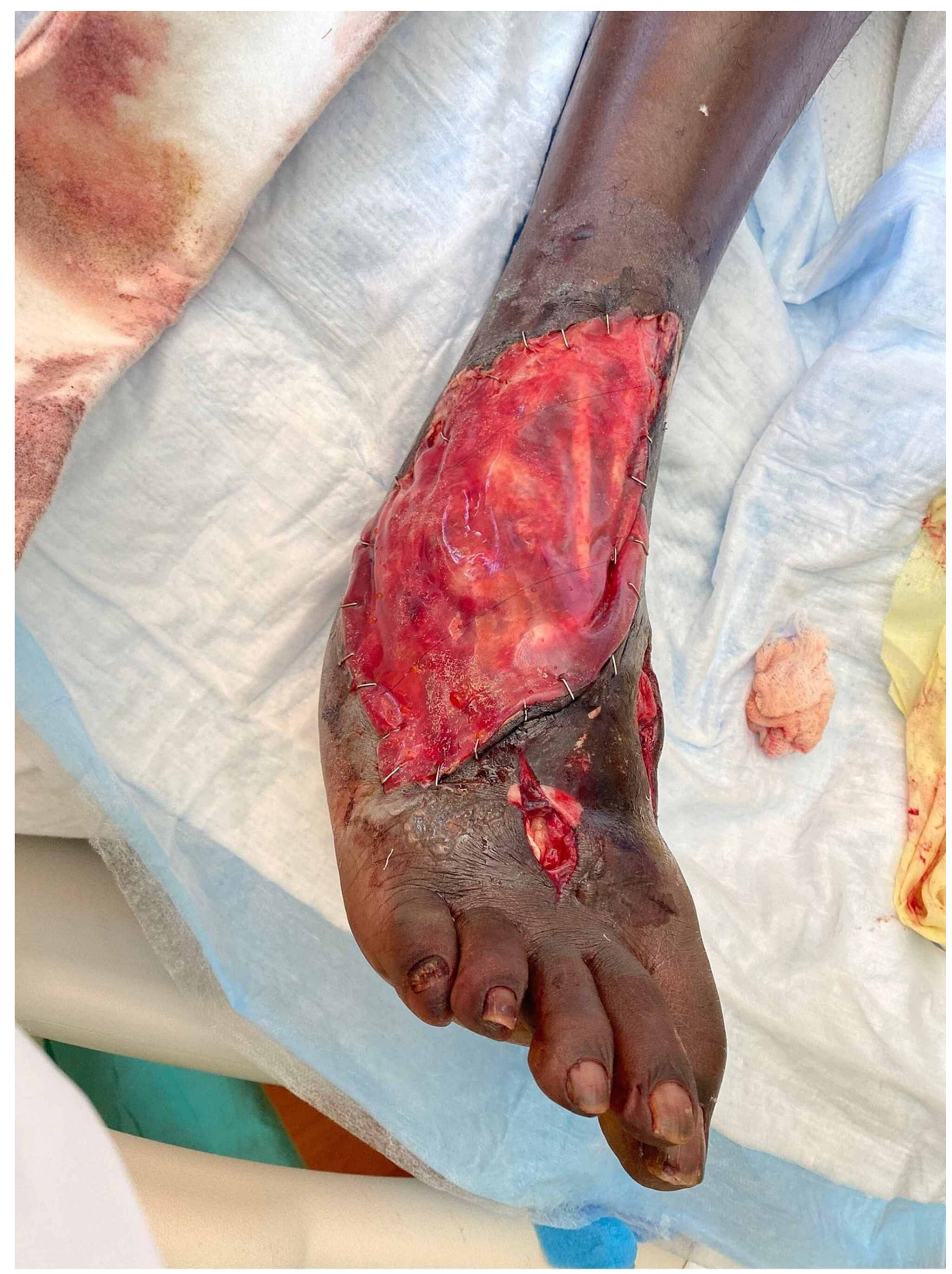

\section{FIGURE 3: Patient's right lower extremity after revascularization and compartment release}

Shown here is the patient's right lower extremity after revascularization of the dorsalis pedis with a saphenous vein interposition graft and coverage with Integra ${ }^{\mathrm{TM}}$ (Integra LifeSciences, Princeton, NJ). Compartment release was performed in the interdigit space. At this time the tissue was dusky but with Doppler signals in the first interdigit webspace.

Postoperatively, the patient's graft was maintained on a heparin infusion. His distal digits remained ischemic, but the patient had palpable pulses distally. Given the concern for continued ischemic insult with disruption of the microvasculature due to crush injury, the patient underwent hyperbaric therapy. Postoperative pictures of the wound are shown in Figure 4. Despite attempts to salvage the forefoot with continued hyperbaric therapy and serial debridement, the patient did require transmetatarsal amputation as shown in Figure 4 on the 19th hospital day before and after Integra ${ }^{\mathrm{TM}}$ placement. The residual foot (and ankle) has remained viable and functional. 


\section{Cureus}

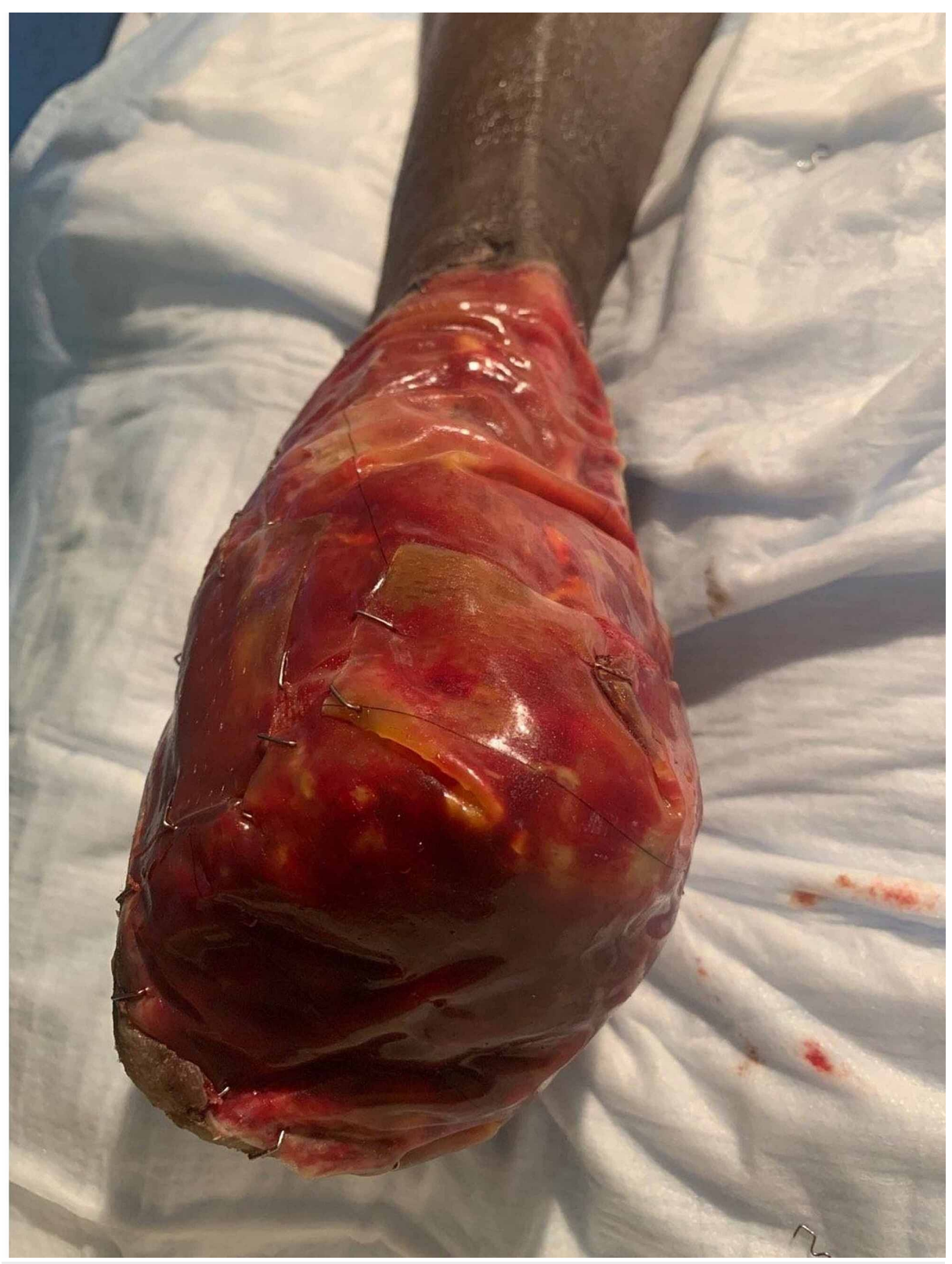

\section{FIGURE 4: Patient's right lower extremity after transmetatarsal amputation}

Here is the remnant of the patient's right lower extremity after transmetatarsal amputation. Despite initial loss of all vascular supply distal to the malleolus the patient was able to have partial extremity salvage due. The wound here has maintained coverage with skin substitute due to lack of available viable tissue.

\section{Discussion}

Primary dorsalis pedis reconstruction is not well described in the current literature. There are several case reports that describe aneurysmal disease after a traumatic crush injury, arterial access complications, and even attributed to repetitive footwear trauma [12-16]. Long-term patency conclusions from this data are difficult to infer; however, saphenous vein bypass to the dorsalis pedis in atherosclerotic disease has been described. In one of the largest retrospective studies of $>1000$ patients, the primary graft utilized was saphenous vein grafts (reversed and nonreversed) with primary patency rates of $56.8 \%$ and limb salvage rates of $78.2 \%$ [17]. It is unclear whether this long-term data is applicable to traumatic limb salvage.

In the authors' review of the literature, the description of dorsalis pedis reconstruction in traumatic arterial transection has not been previously described, regardless of the mechanism of injury. Given the relative lack of anatomic variants within this region with reported dorsalis pedis arterial diameters of 1.9-3.4 mm, including the venous interposition graft for this type of distal extremity trauma into the surgeon's armamentarium is noteworthy. Further, the description of compartment syndrome encountered 
intraoperatively within this patient is also unique. A recent review of current literature on the subject highlighted the heterogeneity in the reported number of compartments and their surgical decompression [18]. In this case study, based on our intraoperative finding of intramuscular hematomas and nonviable tissues within the foot we did create several incisions. While the patient did require transmetatarsal amputation, the level of limb salvage was improved through the attempted limb salvage techniques described here.

\section{Conclusions}

Foot crush injury is a difficult problem both from the complexity of the injury pattern standpoint and also the significant clinical and socioeconomic burden that it represents to the patient. While scoring systems exist to predict limb salvage, the accuracy and implementation of these are varied, and thus clinical judgment must always be employed when attempting limb salvage. We describe the first reported use of a reversed saphenous interposition graft repair of a transected dorsalis pedis in a patient with complex open fractures of the distal tibia and metatarsals in an attempt at limb salvage. While the patient ultimately required transmetatarsal amputation, the authors of this report feel that this intervention may have prevented a below-the-knee amputation and potentially may have a more significant benefit if introduced early in the patient's treatment.

\section{Additional Information \\ Disclosures}

Human subjects: Consent was obtained by all participants in this study. Florida Atlantic University issued approval NA. All single-subject research has been waived for case reports as per our IRB protocols. Conflicts of interest: In compliance with the ICMJE uniform disclosure form, all authors declare the following: Payment/services info: All authors have declared that no financial support was received from any organization for the submitted work. Financial relationships: All authors have declared that they have no financial relationships at present or within the previous three years with any organizations that might have an interest in the submitted work. Other relationships: All authors have declared that there are no other relationships or activities that could appear to have influenced the submitted work.

\section{References}

1. Kauvar DS, Thomas SB, Schechtman DW, Walters TJ: Predictors and timing of amputations in military lower extremity trauma with arterial injury. J Trauma Acute Care Surg. 2019, 87:S172-7. 10.1097/TA.0000000000002185

2. Higgins TF, Klatt JB, Beals TC: Lower extremity assessment project (LEAP) - the best available evidence on limb-threatening lower extremity trauma. Orthop Clin North Am. 2010, 41:233-9. 10.1016/j.ocl.2009.12.006

3. Kauvar DS, Miller D, Walters TJ: Tourniquet use is not associated with limb loss following military lower extremity arterial trauma. J Trauma Acute Care Surg. 2018, 85:495-9. 10.1097/TA.0000000000002016

4. Clay FJ, Newstead SV, Watson WL, McClure RJ: Determinants of return to work following non-lifethreatening acute orthopaedic trauma: a prospective cohort study. J Rehabil Med. 2010, 42:162-9. 10.2340/16501977-0495

5. Scalea JR, Crawford R, Scurci S, et al.: Below-the-knee arterial injury: the type of vessel may be more important than the number of vessels injured. J Trauma Acute Care Surg. 2014, 77:920-5. 10.1097/TA.0000000000000458

6. Kim PH, Leopold SS: In brief: Gustilo-Anderson classification. Clin Orthop Relat Res. 2012, 470:3270-4 10.1007/s11999-012-2376-6

7. Schirò GR, Sessa S, Piccioli A, Maccauro G: Primary amputation vs limb salvage in mangled extremity: a systematic review of the current scoring system. BMC Musculoskelet Disord. 2015, 16:1-7. 10.1186/s12891015-0832-7

8. Loja MN, Sammann A, DuBose J, et al.: The mangled extremity score and amputation: time for a revision . I Trauma Acute Care Surg. 2017, 82:518-23. 10.1097/TA.0000000000001339

9. Darter BJ, Hawley CE, Armstrong AJ, Avellone L, Wehman P: Factors influencing functional outcomes and return-to-work after amputation: a review of the literature. J Occup Rehabil. 2018, 28:656-65. https://doi.org/10.1007/s10926-018-9757-y

10. Penn-Barwell JG: Outcomes in lower limb amputation following trauma: a systematic review and metaanalysis. Injury. 2011, 42:1474-9. 10.1016/j.injury.2011.07.005

11. MacKenzie EJ, Bosse MJ, Kellam JF, et al.: Characterization of patients with high-energy lower extremity trauma. J Orthop Trauma. 2000, 14:455-66. 10.1097/00005131-200009000-00001

12. Sonntag M, Hopper N, Graham AR: ‘Sandal strap' trauma and atherosclerosis are dual pathologies leading to bilateral true aneurysms of the dorsalis pedis arteries. J Vasc Surg. 2013, 57:1391-4. 10.1016/j.jvs.2012.09.066

13. Lee Y, Ryu HY, Kim YJ, Ku GW: Unusual pseudoaneurysm of the dorsalis pedis artery after an iatrogenic injury. Korean J Thorac Cardiovasc Surg. 2018, 51:213-5. 10.5090/kjtcs.2018.51.3.213

14. Erkut B, Ates A: Post-traumatic dorsalis pedis pseudo-aneurysm caused by crush injury . EJVES Short Reports. 2019, 44:29-32. 10.1016/j.ejvssr.2019.07.003

15. Ballesteros-Pomar M, Sanz-Pastor N, Vaquero-Morillo F: Repair of bilateral true aneurysms of the dorsalis pedis artery. J Vasc Surg. 2013, 57:1387-90. 10.1016/j.jvs.2012.09.070

16. Vlachovsky R, Staffa R, Novotny T: Pseudoaneurysm of the dorsalis pedis artery: case report and literature review. J Foot Ankle Surg. 2017, 56:398-400. 10.1053/j.jfas.2016.10.009

17. Pomposelli FB, Kansal N, Hamdan AD, et al.: A decade of experience with dorsalis pedis artery bypass: 


\section{Cureus}

analysis of outcome in more than 1000 cases. J Vasc Surg. 2003, 37:307-15. 10.1067/mva.2003.125

18. Lutter C, Schöffl V, Hotfiel T, Simon M, Maffulli N: Compartment syndrome of the foot: an evidence-based review. J Foot Ankle Surg. 2019, 58:632-40. 10.1053/j.jfas.2018.12.026 